\title{
A New Recursive Filtering Method of Terrestrial Laser Scanning Data to Preserve Ground Surface Information in Steep-Slope Areas
}

\author{
Mi-Kyeong Kim ${ }^{1}$, Sangpil Kim ${ }^{1}$, Hong-Gyoo Sohn ${ }^{1, *}$, Namhoon Kim ${ }^{1}$ and Je-Sung Park ${ }^{2}$ \\ 1 Department of Civil and Environmental Engineering, Yonsei University, Seoul 03722, Korea; \\ kimmikyeong@yonsei.ac.kr (M.-K.K.); spkim09@yonsei.ac.kr (S.K.); kim_namhoon@yonsei.ac.kr (N.K.) \\ 2 National Disaster Management Research Institute, Ulsan 44538, Korea; jesung0225@korea.kr \\ * Correspondence: sohn1@yonsei.ac.kr; Tel.: +82-2-2123-2809
}

Received: 10 October 2017; Accepted: 13 November 2017; Published: 15 November 2017

\begin{abstract}
Landslides are one of the critical natural hazards that cause human, infrastructure, and economic losses. Risk of catastrophic losses due to landslides is significant given sprawled urban development near steep slopes and the increasing proximity of large populations to hilly areas. For reducing these losses, a high-resolution digital terrain model (DTM) is an essential piece of data for a qualitative or a quantitative investigation of slopes that may lead to landslides. Data acquired by a terrestrial laser scanning (TLS), called a point cloud, has been widely used to generate a DTM, since a TLS is appropriate for detecting small- to large-scale ground features on steep slopes. For an accurate DTM, TLS data should be filtered to remove non-ground points, but most current algorithms for extracting ground points from a point cloud have been developed for airborne laser scanning (ALS) data and not TLS data. Moreover, it is a challenging task to generate an accurate DTM from a steep-slope area by using existing algorithms. For these reasons, we developed an algorithm to automatically extract only ground points from the point clouds of steep terrains. Our methodology is focused on TLS datasets and utilizes the adaptive principal component analysis-triangular irregular network (PCA-TIN) approach. Our method was applied to two test areas and the results showed that the algorithm can cope well with steep slopes, giving an accurate surface model compared to conventional algorithms. Total accuracy values of the generated DTMs in the form of root mean squared errors are $1.84 \mathrm{~cm}$ and $2.13 \mathrm{~cm}$ over the areas of $5252 \mathrm{~m}^{2}$ and $1378 \mathrm{~m}^{2}$, respectively. The slope-based adaptive PCA-TIN method demonstrates great potential for TLS-derived DTM construction in steep-slope landscapes.
\end{abstract}

Keywords: TLS; ground filtering; landslide; steep slope

\section{Introduction}

Landslide, defined as a rapid downward movement of a mass of rock, earth, or artificial fill on a slope [1], has a great impact on the overall environment; including the natural environment and human society [2]. Throughout the ages, development and settlement on steep slopes has increased the risk of landslides [3]. The June 2017 landslide in Sichuan Province, China, caused more than 15 deaths and 100 people to be classified as missing [4]. Another recent landslide in August of 2017 in Sierra Leone killed an estimated 300 people; at least 300 to 1500 people are still classified as missing [5]. A huge landslide in Umyeonsan area of Seoul, Korea, swept through one of the Seoul's most affluent neighborhoods in July 2011 [6]. It caused an unprecedented loss to the urban area. About half of the 120 households in Hyeongchon village were damaged and 18 people were killed [7]. These kinds of unusual landslides have been increasing in frequency and causing considerable economic loss as well as casualties. 
In order to minimize the losses caused by landslides, it is essential to monitor steep slopes and predict the possibilities of landslides. For this reason, technologies for reducing landslide risks have gained special attention from many decision-makers and researchers [8,9]. The key factor to monitor a steep slope is to find out the critical elements out of the various factors for a landslide to occur. Much research has been carried out to find the main causes of landslides. Many critical factors such as slope geometry, geology, soil characteristics, and vegetation conditions of the concerned areas have been identified as the root causes of landslides [10-12]. Among those elements, bare earth information of a steep slope is one of the key data for further analysis of a potential landslide; detecting, modelling and monitoring landslide features $[10,13,14]$.

High resolution topographic models, significant data for bare earth information, are mostly obtained from Light Detection and Ranging (LiDAR) observations [15,16]. LiDAR systems can measure ranges (distances) to the object and other properties by using light in the form of a pulse laser [17]. LiDAR data is commonly acquired by airborne laser scanning (ALS) or terrestrial laser scanning (TLS). ALS data, which is acquired from a nadir field of view, has been widely used in large-scale areas. On the other hand, TLS data is acquired from an oblique view and has a high resolution which is hardly obtained from ALS $[16,18]$. Therefore, TLS has been increasingly used to capture terrain features in recent years [16]. This is because the highly detailed digital terrain model (DTM), with millimeter precision and accuracy, can be generated from TLS data [19]. DTM, an elevation surface representing the bare earth referenced to a common vertical datum, has been a prerequisite in many occasions for hazard analysis, particularly in mountainous areas [6,7].

Although TLS data has been accepted as a major data source in recent years, a point cloud acquired by the LiDAR system usually includes unnecessary objects such as vegetation [20]. In this case, an accurate DTM can be generated after removing non-ground object points from the point cloud. Therefore, filtering, which is the process of removing unwanted object information from a point cloud, is necessary prior to generating a final user-required DTM. Through the filtering process, a new set of point clouds, which returns from the ground surface, is extracted by separating terrain returns from off-the-terrain objects. However, it is challenging to extract terrain surface information, especially in a wooded, mountainous area, from LiDAR observations [21-23]. This is because fewer ALS points hit the surface of the earth or the height difference is significant over a small horizontal distance [21,24].

In order to extract ground points from a point cloud, a range of filtering methods have been proposed. Research on developing algorithms to determine whether the points out of a point cloud are from terrain or not have been suggested by comparing height difference, slope angle, surface curvature, and signal intensity with their neighboring points for ALS data [25-29]. There has also been research conducted to summarize the merits and demerits of existing filtering algorithms of a point cloud by comparing and analyzing them for ALS data [22,30,31].

The filtering methods for ALS data have been increasingly studied [31]. Current filtering algorithms developed for ALS can be divided into three main categories; slope-based, morphology-based, and surface interpolation-based approaches [22,32-35]. The slope-based filters $[28,36]$ assume that the slope between terrain points is gradual. If a slope between two points is large, the point at the highest elevation is regarded as a non-ground point. Morphological filters $[37,38]$ begin with the assumption that the ground is flat. Surface interpolation-based filters [39-41] assume that the terrain can be approximated by parametric surfaces. Previous studies $[30,35]$ ascertained that surface interpolation-based filters performed better than the others, but with a limitation in steep-slope landscapes. It has been a challenging and an intriguing task for researchers to develop a filtering algorithm that works precisely for steep mountainous terrain $[24,27,29]$.

In case of steep-slope landscapes, the bare earth information of a terrain is critical for analyzing the risk of landslide. Even though ALS data with a bird's-eye view of the terrain has proven to be useful to obtain terrain surface [42], TLS is advantageous over ALS in detecting small detailed surface information on a steep-slope terrain. However, the properties of TLS datasets are different from those of ALS, such as geometry of data acquisition (a lateral view of a terrain), point density, and point cloud properties [19,43]. 
Due to the different characteristics between ALS and TLS datasets, it is challenging to directly apply the filtering algorithms developed for ALS datasets to TLS datasets [19,34,44,45]. Moreover, with existing algorithms for ALS datasets, it is difficult to properly extract the lateral view information of a steep slope. The lateral view information of a steep slope is critical to identifying the risk of landslide.

Motivated by those issues, we propose a new recursive filtering algorithm for extracting ground points from TLS point clouds acquired from hilly and vegetated areas. Our research is focused on developing an automatic filtering method using range information of TLS data to generate the DTMs, which provide accurate terrain morphology information. The results of the proposed filtering algorithm can be readily used in analyzing instability and improving the quality of a surface model and the risk analysis of landslide in steep slope terrains.

\section{Research Areas and Datasets}

\subsection{Study Area}

Korea, with $70 \%$ of the land covered by mountains, has started a project to repair risky areas with steep slopes under the initiative of the former MPSS (Ministry of Public Safety and Security). In accordance with the "Prevention of Steep Slope Disasters Act" [46], the mayors and municipal governors designated and announced areas that constitute a steep slope that has a high risk of collapse and may cause human injury as a hazardous area through a safety inspection. Accordingly, the MPSS has carried out maintenance work for safety management and risk-of-collapse of the steep-slope areas via annual periodical safety inspections [47]. As part of this project, three-dimensional data over the potential risky areas of the steep-slope areas have been acquired.

Two different sites with different surface morphology were selected as research areas, as shown in Figure 1. The first site is located in the Somang Hospital District, Gwangju, Korea. In this area, a warehouse of $5 \mathrm{~m}^{2}$ was damaged due to a landslide that occurred in December 2015. The area received a D grade through the MPSS's evaluation system [48]. The MPSS categorizes the risk level of steep-slope areas into five grades from $\mathrm{A}$ to $\mathrm{E}$, among which $\mathrm{E}$ is for the riskiest slopes. Essentially, the lower the grade, the more attention from the government is required. The second experiment was carried out in the Chunghak District, located in Busan, Korea. This site received an evaluation grade of $C$ and exhibited different surface characteristics compared with the first site. More detailed explanations about the sites follow.
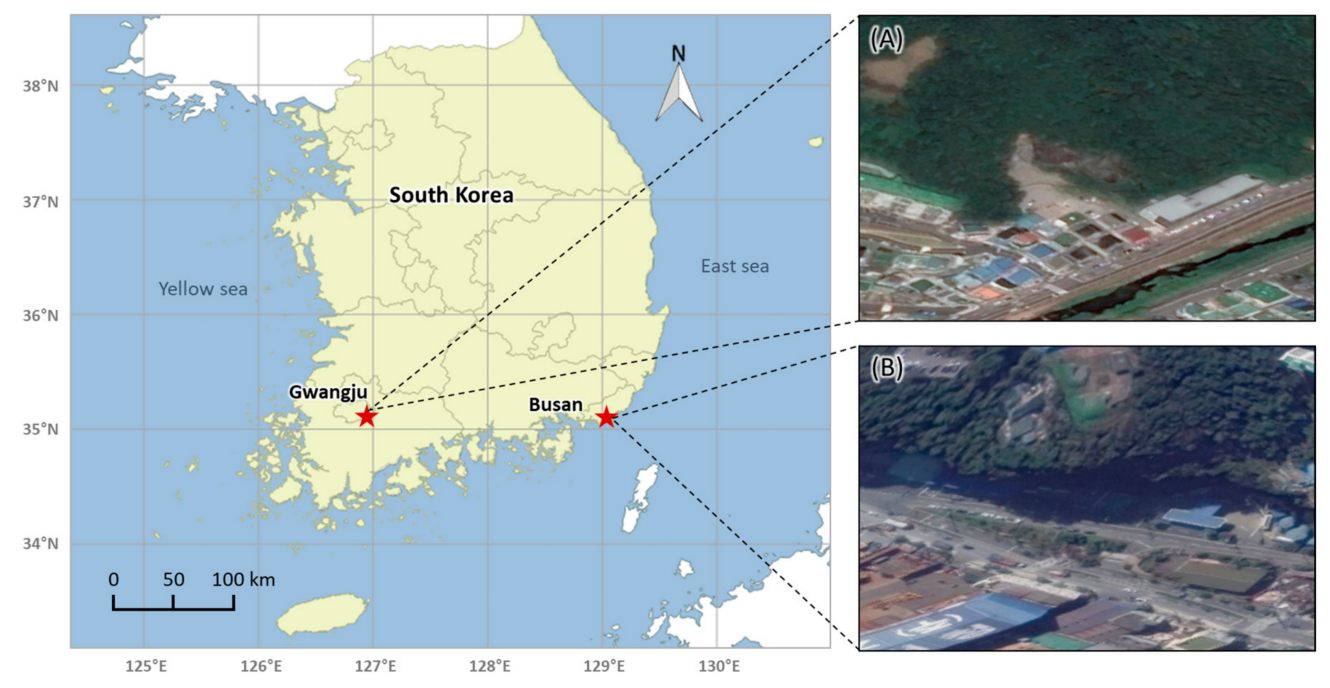

Figure 1. Map showing the study areas: (A) located in Gwangju and (B) located in Busan.

Both experimental sites have extremely high slope areas but the ground surface condition and overall morphology are very different from one another: (A) the first site consists of rock and almost no 
vegetation on its side, but much vegetation on its outskirts; (B) the second site is significantly covered with vegetation. The top-view images of the two sites are shown in Figure 1; site A and B images are acquired from Google Earth.

\subsection{Data Description}

Data was acquired by the Riegl VZ-2000 scanner, which has a maximum range of $2050 \mathrm{~m}$ (@ 90\% albedo), a laser spot size of $0.3 \mathrm{mrad}$, and an accuracy and precision of 8 and $5 \mathrm{~mm}$ (@ $150 \mathrm{~m}$ ), respectively [49]. Full datasets over the two sites were acquired using the RiSCAN PRO software (Riegl, Horn, Austria) [50]. We extracted a portion of the full datasets from each site to test our proposed filtering algorithm. Table 1 shows the statistics of the extracted TLS datasets used in this study. As shown in Table 1, the number of point clouds for each site was about 2.5 million and 4 million points and the areas covered were $5252 \mathrm{~m}^{2}$ and $1378 \mathrm{~m}^{2}$, respectively. The maximum and minimum height of the covered areas were $64.85 \mathrm{~m}$ and $-8.76 \mathrm{~m}$, respectively. Each dataset was acquired using the local machine coordinate system (i.e., Riegl TLS coordinate system).

Table 1. Terrestrial laser scanning dataset statistics of study areas.

\begin{tabular}{ccccccc}
\hline \multirow{2}{*}{ Category } & \multirow{2}{*}{ Number of Points } & \multirow{2}{*}{ Area $\left(\mathbf{m}^{\mathbf{2}}\right)$} & \multirow{2}{*}{ Mean Slope $\left(^{\circ}\right)$} & \multicolumn{3}{c}{ Height $(\mathbf{m})$} \\
\cline { 5 - 7 } & & & & Maximum & Minimum & Average \\
\hline Site A & $2,519,944$ & 5252 & 36.61 & 64.85 & -1.88 & 26.16 \\
Site B & $3,966,393$ & 1378 & 41.20 & 35.68 & -8.76 & 8.52 \\
\hline
\end{tabular}

Figure 2 depicts the street view of the two study areas. The left-hand side of the image represents site $\mathrm{A}$ and the right-hand side of the image depicts site $\mathrm{B}$. The images were acquired from NAVER Map (http:/ / map.naver.com), which provides street-view images taken from ground-based vehicles. As shown in Figure 2, both of our study areas exhibit very steep slopes, which are close to cliffs, and vegetation exists universally over the test area. Vegetation and other information, except the terrain, were considered as noise in our case and removed manually to obtain the bare ground surfaces of each site. The manually noise-removed point cloud datasets were regarded as the ground truth data and further used for the validation for our proposed algorithm.

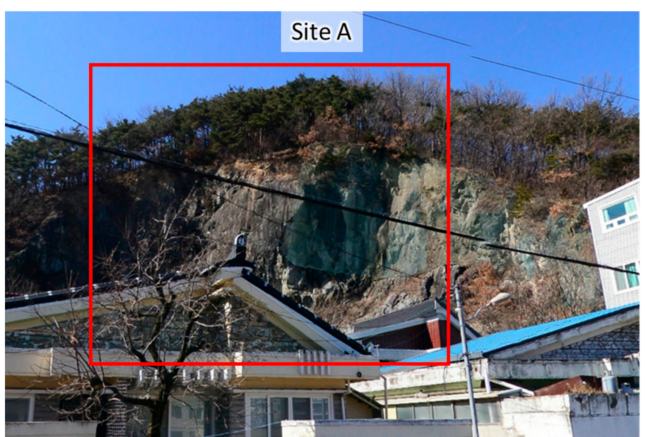

(a)

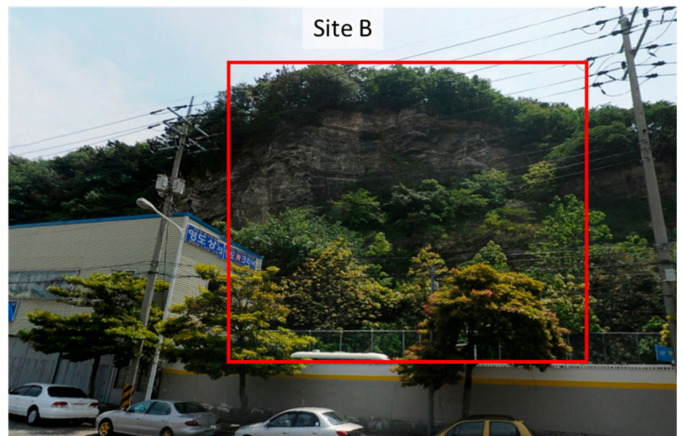

(b)

Figure 2. Lateral view of the study areas from the ground (street view of NAVER); (a) site A; (b) site B.

\section{Recursive Filtering Method}

As shown in Figure 3, a steep slope with vegetation can be categorized into two cases; first, a case where the slope of a ground gradually increases, and second, a case where the slope of a ground increases rapidly. Since the main focus of our filtering algorithm is to extract ground surface information, non-ground surface information such as trees, houses, and other facilities are regarded as noise. 


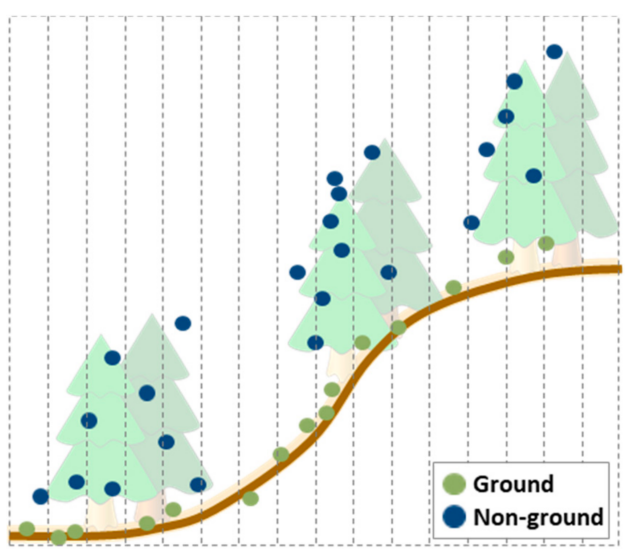

(a)

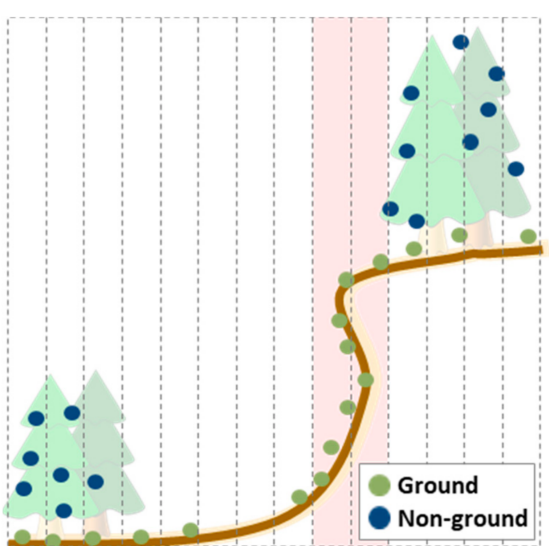

(b)

Figure 3. Steep slope site characteristics: (a) a case where the slope of the ground gradually increases; (b) a case where the slope of the ground increases rapidly.

A simple ground filtering algorithm, which is frequently applied to ALS data, finds the lowest elevation value from the point cloud. In the TLS case, many ground points are lost during the noise removal approach with the lowest elevation value at the position where the inclination of slope changes abruptly. It is concluded that a more sophisticated algorithm which incorporates not only the lowest elevation category but also the abrupt slope changes is required. We propose a recursive filtering method that is depicted schematically in Figure 4. Figure 4 shows the overall procedures of our algorithm. The basic concept of our approach is to find the minimum height values after identifying an optimum rotating axis of the original point cloud. The reason for conducting a two-step process is that most of current available algorithms fail to keep the terrain surface in steep slopes. Each step of our recursive method is explained in detail in the following.

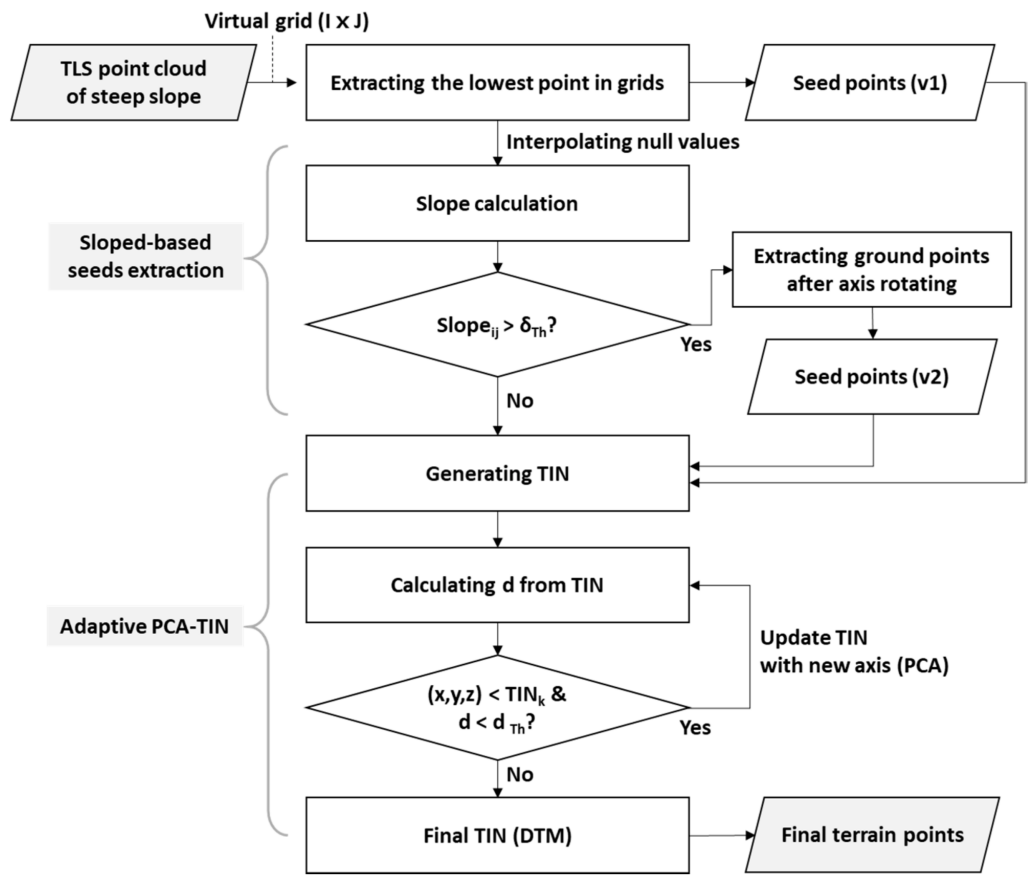

Figure 4. A flowchart of the proposed filtering algorithm (TIN; triangulated irregular network, PCA; principal component analysis, I; the number of rows of virtual grid, J; the number of columns of virtual grid, Slope $i_{i, j}$; slope angle of $(i, j)$ in virtual grid, $\delta_{\mathrm{Th}}$; slope angle threshold, $\mathrm{TIN}_{\mathrm{k}} ; k$ th triangle, $d$; distance between a target point $(x, y, z)$ and $\operatorname{TIN}_{\mathrm{k}}, d_{\mathrm{Th}}$; threshold value of $d$ ). 


\subsection{Slope-Based Seed Points Extraction}

Previous studies applied the slope-based approach using a threshold value of slopes to distinguish ground points from non-ground points. However, these slope-based filters could not obtain a good result in the steep-slope areas because of using a single fixed slope threshold [35]. In the mixed-slope area, where flat and hilly areas are interspersed, using a fixed threshold value can miss much of the ground information [35]. To overcome the limitation of previous approaches, our approach splits the extraction of the ground surface process into three steps; the extraction of the lowest point, the calculation of a slope angle, and the extraction of ground points after the rotation of the axis.

\subsubsection{Extracting the Lowest Point}

In this study, by generating a virtual grid, a minimum height value of the corresponding grid is extracted. To generate the virtual grid, the initial size of the grid is set to $1 \mathrm{~m} \times 1 \mathrm{~m}$. The size of the initial grid can be varied depending on the size or the range of the input data sets. A virtual grid was created on the X-Y plane, and the lowest point in the grid (height) was extracted as shown in Figure 5. It shows the $\mathrm{X}-\mathrm{Z}$ plane of a steep slope, on which the red dots represent the lowest point of each grid.

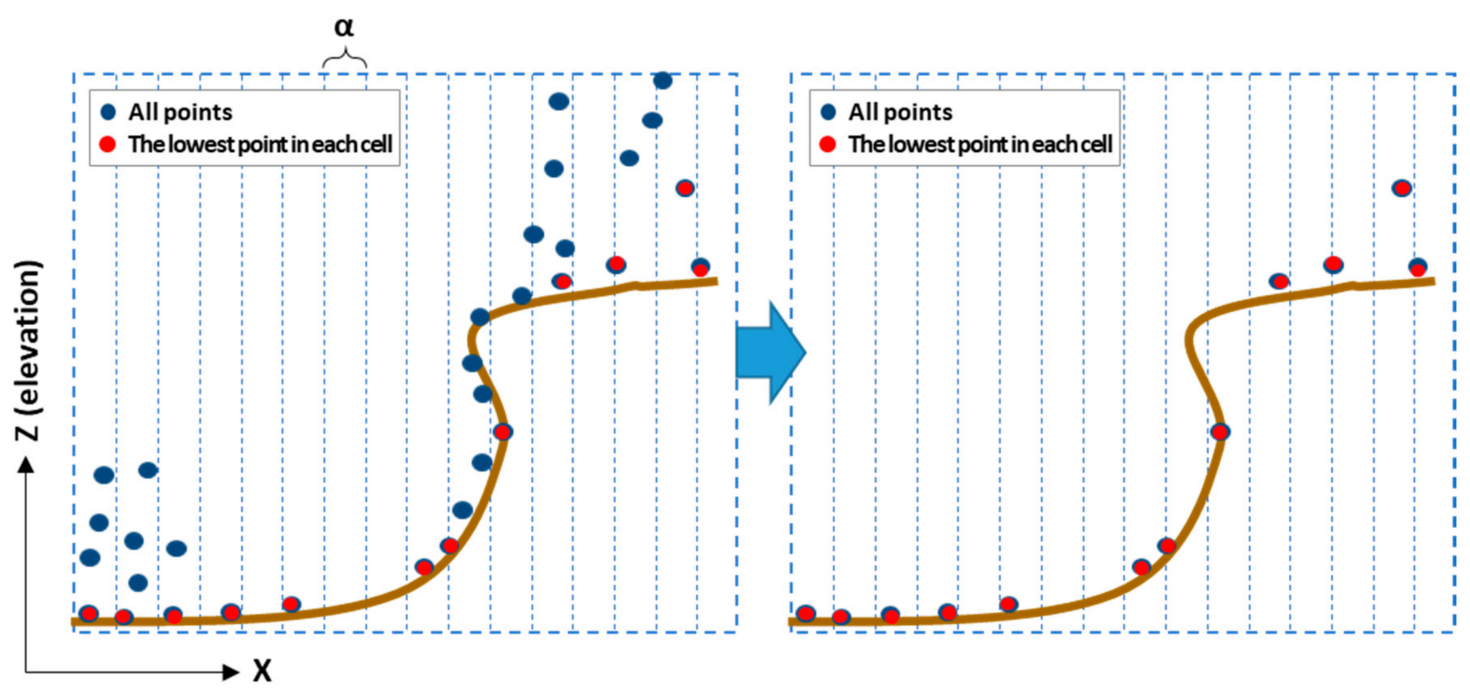

Figure 5. Extracting the lowest point in each grid ( $\alpha \times \alpha$ spacing on $X-Y$ plane).

\subsubsection{Slope Angle Calculation}

Since the extracted points are based on the minimum height, there may not be any point on the portion in which the slope changes radically on the steep slope. To resolve this problem, we utilize slope angles to add new points to the initial seed points (seed points v1 in Figure 4). To calculate slope angles, the initial DTM is generated using the initial seed points and then interpolated. Interpolation is necessary to prevent the height value of the initial DTM from having a null value when there is no point in a particular grid because the grid has a low point density. Once the initial DTM has been interpolated, slope angles in each grid are calculated from the DTM.

\subsubsection{Extracting Ground Points after Axis Rotation}

In the case of a high slope value; if only the point having the minimum height in the corresponding grid is extracted, the shape of the ground of the steep slope cannot be accurately extracted (Figure 5). Therefore, for a cell over a certain slope $\left(\delta_{\mathrm{Th}}\right.$; slope angle threshold in Figure 4$)$, the lowest point of each cell is extracted from the rotated axis based on the fitted plane in the corresponding cells (Figure 6a). Through this process, the side points of the portion where the slope changes abruptly are also extracted 
as seed points (Figure $6 \mathrm{~b}$ ). The slope angle threshold value depends on the data characteristics. In this study, $60^{\circ}$, which is more than the average slope value, was determined as slope angle threshold through experiments.

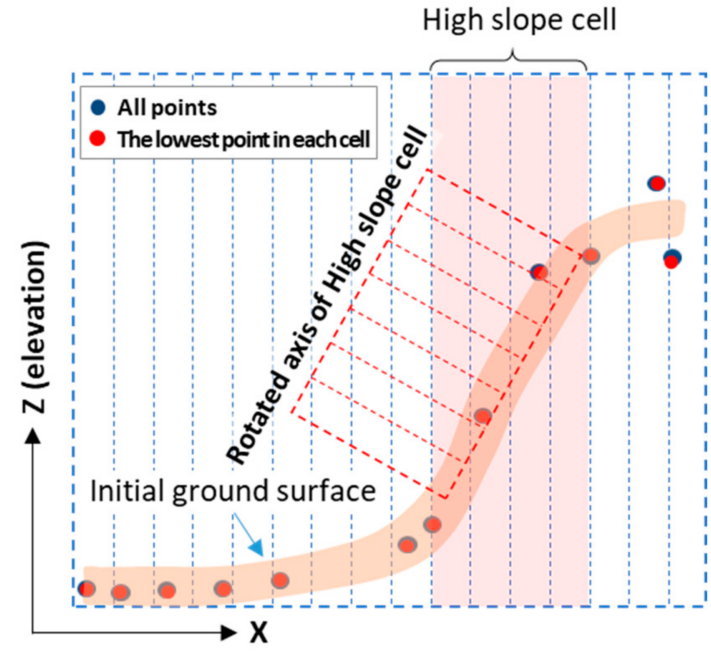

(a)

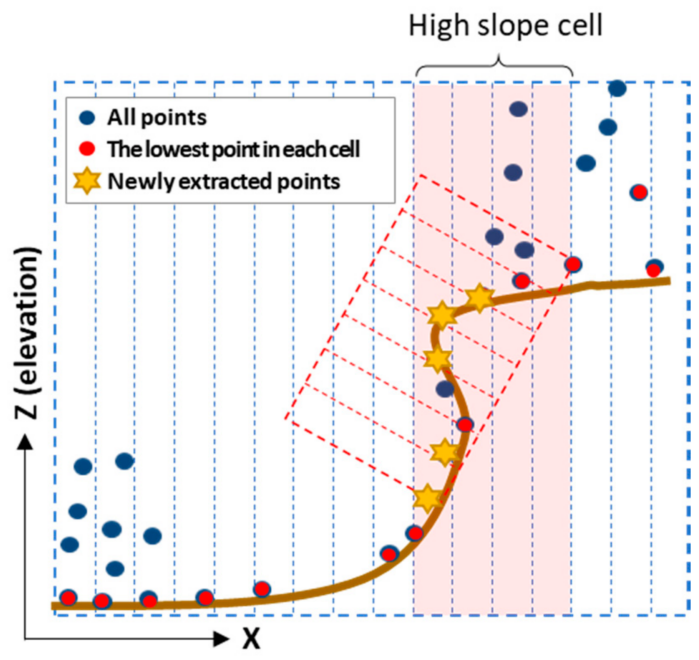

(b)

Figure 6. Extracting ground points after axis rotation in high slope cells: (a) rotating axis of high slope cell; (b) newly extracted points.

\subsection{Adaptive PCA-TIN}

This step consists of extracting additional ground points by constructing TINs using the seed points. TIN-based filtering is a method used to estimate the initial ground from the initial TIN and increase the ground point density by gradually adding ground points from it. This method is called adaptive TIN, which shows a stable performance when compared with other filtering methods [34]. However, since the traditional model is $2.5 \mathrm{D}$, the real terrain information along the steep slope surface is lost, leading to significant simplification [51]. Hence, we applied the principal component analysis (PCA) before generating the TIN model. The main purpose of applying PCA is to find and rotate the axis with maximum variances where the point cloud is most distributed. If the point cloud is transformed to the principal axis before generating TIN, we can prevent the side information of the steep slope surface from being lost. This process is called adaptive PCA-TIN and the details are as follows.

\subsubsection{Initial TIN after Rotating the Axis}

Since the steep slope has a high degree of curvature and slope, it was evaluated that grid-based filtering in $2.5 \mathrm{D}$ alone could not adequately describe the terrain. Accordingly, we applied TIN after rotating the axis to complement the existing method. First, the principal plane of the seed points is determined, and then a virtual grid is generated for the principal plane. Second, the ground point having the minimum height value is extracted in the grid to construct the initial TIN.

\subsubsection{Adding Points for the Next TIN}

In this step, only the points that satisfy certain criteria are selected as candidates for updating the next TIN. The first criterion is the vertical distance from the TIN and the second one is whether the points are in the TIN plane or not. The threshold value (vertical distance) is generally the median of the histograms of the vertical distances of all the candidate points. Candidates below the threshold value are classified as ground points. Figure 7 shows the point selection process for updating TIN. 


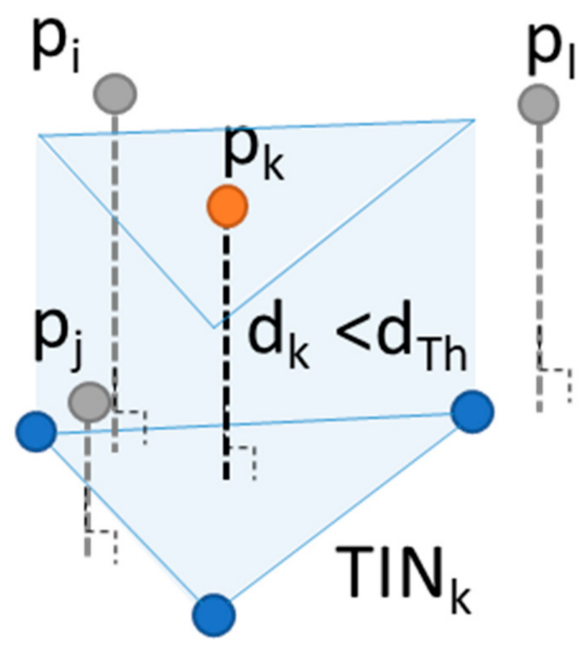

Figure 7. Criteria for adding new points.

\subsubsection{Reconstructing TIN with New Axis (PCA)}

The next TIN are regenerated using the added ground points. The important point in this step is that the TIN is rotated into the principal axis when it is generated. Then the step described in Section 3.2.2 is repeated. These steps (generating TIN with a new axis and adding points) are repeated until there is no candidate point classified as a ground, and the TIN and the histogram are renewed. Finally, all the point clouds are classified as ground and non-ground.

\subsection{Accuracy Assessment}

The accuracy of the proposed filtering method was tested by comparing the final DTM with the reference DTM. The reference DTM was generated by using a point cloud after manually removing noise. In order to analyze the filtering results, the results of the filtering output and the reference data were interpolated to a grid. By changing the grid size, we yielded a final DTM and a reference DTM. Using these DTMs, the discrepancies between them were calculated using Equation (1).

$$
d_{i}\left(x_{i}, y_{i}\right)=h_{\text {final }}\left(x_{i}, y_{i}\right)-h_{\text {reference }}\left(x_{i}, y_{i}\right)
$$

where $d_{i}$ represents the discrepancies between reference elevation value $h_{\text {reference }}$ and output elevation value $h_{\text {final }}$ at coordinate $\left(x_{i}, y_{i}\right)$. The discrepancies were used to calculate the root mean square error (RMSE) and the mean bias error (MBE) to assess the accuracy of the final DTMs within each test area using Equations (2) and (3).

$$
\begin{gathered}
\text { RMSE }=\sqrt{\left(\frac{\sum_{1}^{n} d_{i}^{2}}{n}\right)} \\
M B E=\frac{\sum_{1}^{n} d_{i}}{n}
\end{gathered}
$$

where $n$ is the number of pixels (observations).

\section{Results and Discussion}

In this section, we present the results of the proposed algorithm and discuss the accuracy assessment. Accuracy of the algorithm was evaluated by visual inspection and by comparing errors obtained using the produced DTM with the reference DTM.

The performance of the algorithm was assessed by visual inspection of the final filtering results and comparison with the results of other methods available in nonproprietary software; adaptive 
TIN (ATIN) [25] implemented in LASTools (http://rapidlasso.com/lastools), the weighted linear least-squares interpolation-based method (WLLI) [40] in FUSION (http: / forsys.cfr.washington.edu/ fusion/fusionlatest.html), and the cloth simulation filter (CSF) [52] in CloudCompare (http:/ /www. danielgm.net/cc).

From visual inspection, we could evaluate how realistically the DTM visualized the terrain. Results are shown in Figures 8 and 9. Figure 8 shows the intermediate and final results for the first study area, site A. Figure 8 a shows the original data, and the final result of the ground point extraction is shown in Figure 8d. Figure 8b shows the lowest points before applying slope-based point extraction, and Figure $8 \mathrm{c}$ depicts the seed points for adaptive PCA-TIN. Since the seed points are supplemented by the slope-based point extraction procedure, it could be seen that the ground points were extracted clearly even in the areas where the slopes changed abruptly. However, some errors are included in areas where the point density is low. In case of site A, the density of points in the outer part is relatively low and there is a lot of vegetation. Figure 9 shows the filtering result for site B, which is the same as Figure 8 . In the case of site $B$, although the overall point density is high, a lot of ground points were not obtained because of the thick vegetation. Except for the part where ground points are not well acquired, it could be seen that significant terrain features such as the suddenly rising hill or ridge are represented.

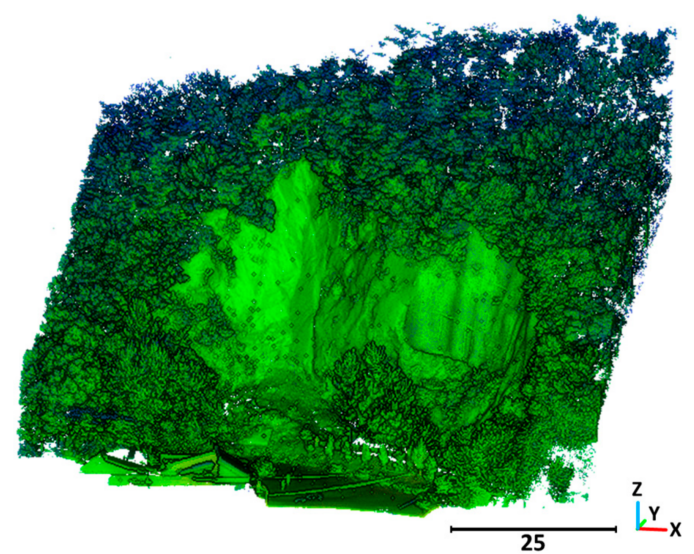

(a)

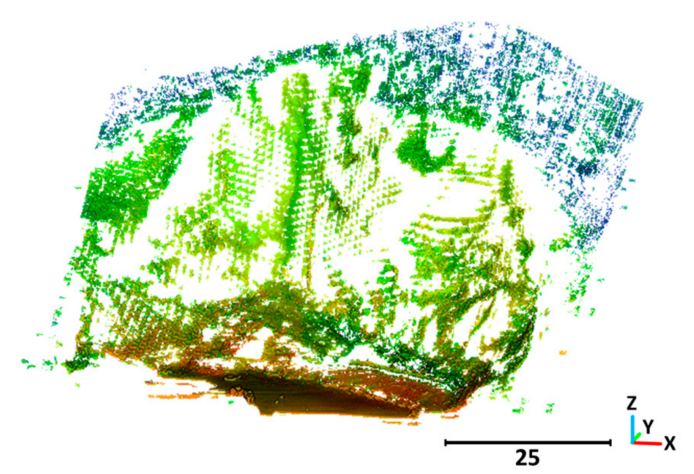

(c)

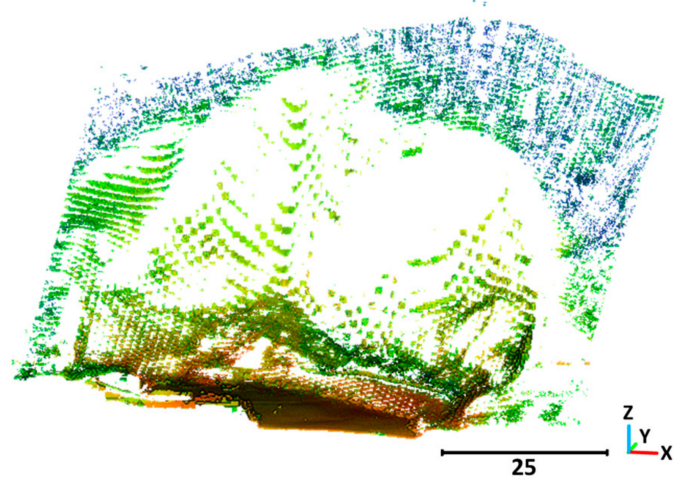

(b)

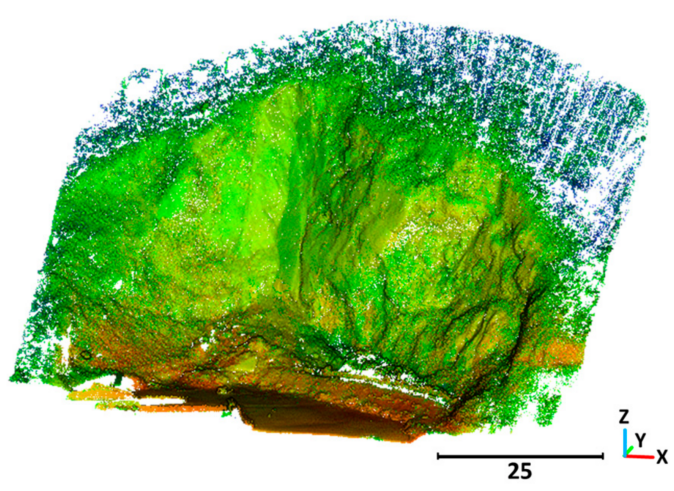

(d)

Figure 8. Filtering result of site A: (a) original data; (b) the lowest points; (c) seed points for PCA-TIN (Principal Component Analysis-Triangular Irregular Network); (d) final result. 


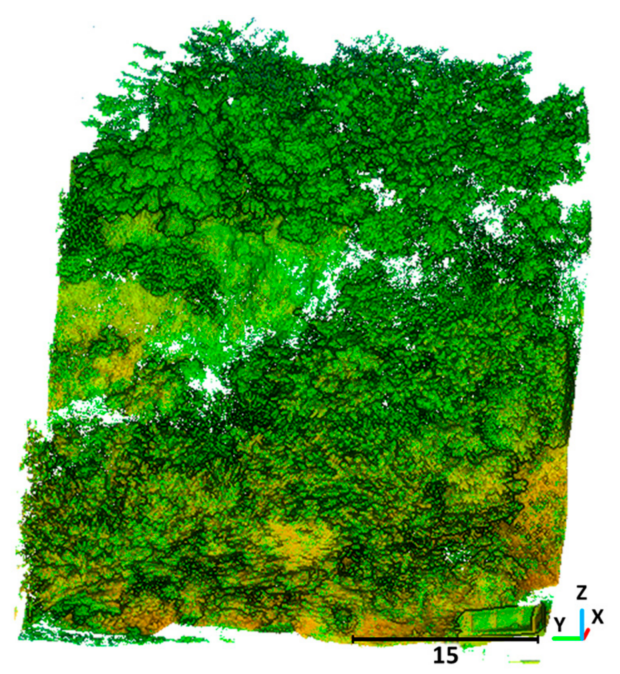

(a)

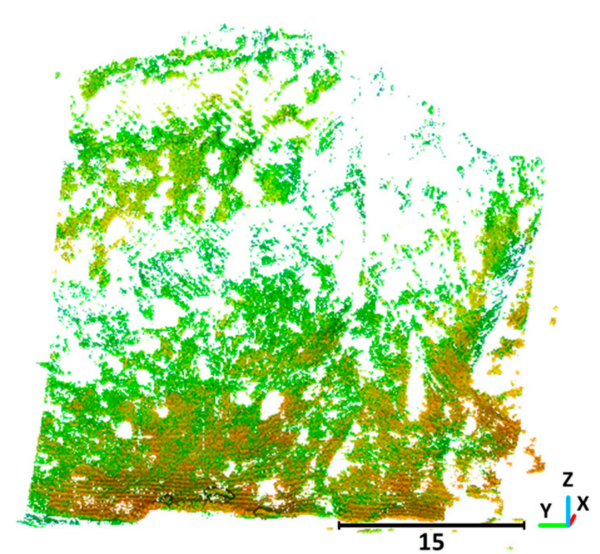

(c)

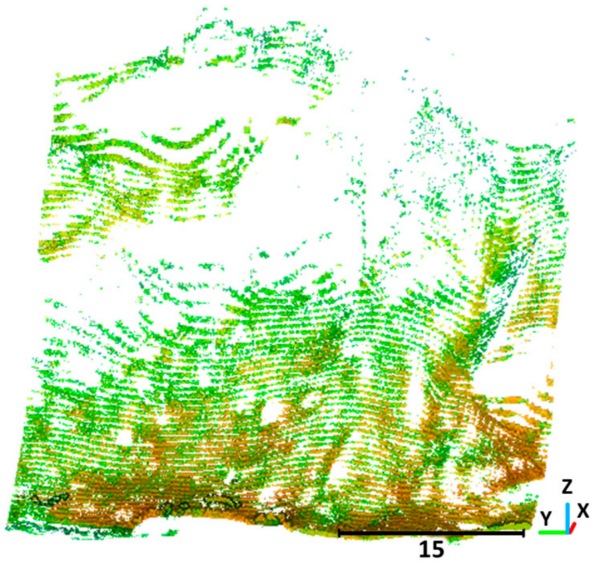

(b)

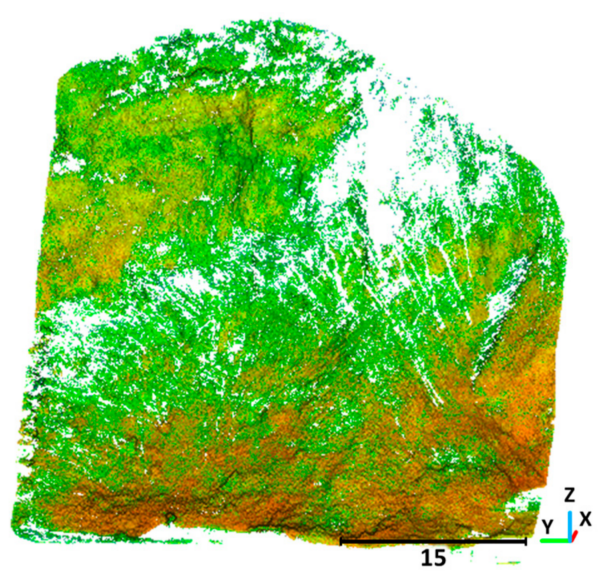

(d)

Figure 9. Filtering result of site B: (a) original data; (b) the lowest points; (c) seed points for PCA-TIN; (d) final result.

The filtering results showed that the proposed algorithm caused commission errors along edge areas; non-ground points (vegetation) were wrongly classified as ground points. This is because the points in the edge area were extracted while the TIN was formed at the edge of the region where the gradient changed abruptly. On the other hand, compared to the commission error, the omission error seems to be relatively small.

For accuracy assessment, we compared the DTMs obtained using different algorithms and those computed from DTMs using reference data. With the filtered ground points from different algorithms, 10-cm DTMs were generated. The initial settings for each filtering algorithm are as follows; terrain type: nature, preprocessing: extra-fine (ATIN), cell size for intermediate surfaces: $1 \mathrm{~m}$ (WLLI), scene: steep slope, cloth resolution: 0.1 , maximum iteration: 500, classification threshold: 0.5 (CSF). These values were determined experimentally.

Table 2 and Figure 10 represent filtering results from each algorithm. As shown in Table 2, the RMSE for the DTM using the proposed algorithm was $1.84 \mathrm{~cm}$ and $2.13 \mathrm{~cm}$ in site A and site B, respectively. The proposed algorithm showed better performance than the other algorithms. Moreover, the data missing ratio, which means the percentage of missing cells in the DTM, is the smallest in the results of proposed algorithm. In case of the results of site B, WLLI showed much smaller RMSE 
and MBE values than the others. However, the RMSE values should be taken as a relative measure of the performance of our algorithm. This is due to the presence of uncertainty in manually filtering and the exception of data missing cells.

Table 2. Comparison of filtering results.

\begin{tabular}{|c|c|c|c|c|c|c|}
\hline Category & $\begin{array}{c}\text { Number of } \\
\text { Points }\end{array}$ & $\begin{array}{l}\text { Filering } \\
\text { Method }\end{array}$ & $\begin{array}{l}\text { Extracted Points } \\
\text { as Ground }\end{array}$ & $\begin{array}{l}\text { RMSE (Root } \\
\text { Mean Squared } \\
\text { Error) (cm) }\end{array}$ & $\begin{array}{c}\text { MBE } \\
\text { (Mean Bias } \\
\text { Error) }(\mathrm{cm})\end{array}$ & $\begin{array}{l}\text { Data Missing } \\
\text { Ratio (\%) }\end{array}$ \\
\hline \multirow{5}{*}{ Site A } & \multirow{5}{*}{$2,519,944$} & ATIN (adaptive TIN) & 515,543 & 18.22 & 8.79 & 36.25 \\
\hline & & WLLI (weighted linear & & & & \\
\hline & & $\begin{array}{l}\text { least-squares } \\
\text { interpolation-based method) }\end{array}$ & 519,321 & 4.00 & 1.34 & 29.90 \\
\hline & & CFS (cloth simulation filter) & 595,257 & 2.72 & 1.38 & 23.51 \\
\hline & & Proposed method & 531,077 & 1.84 & 1.07 & 9.62 \\
\hline \multirow{4}{*}{ Site B } & \multirow{4}{*}{$3,966,393$} & ATIN & 561,563 & 36.30 & 27.69 & 23.40 \\
\hline & & WLLI & 844,003 & 0.71 & 0.08 & 23.87 \\
\hline & & CFS & 782,799 & 2.81 & 2.09 & 18.07 \\
\hline & & Proposed method & 553,850 & 2.13 & 1.45 & 1.25 \\
\hline
\end{tabular}

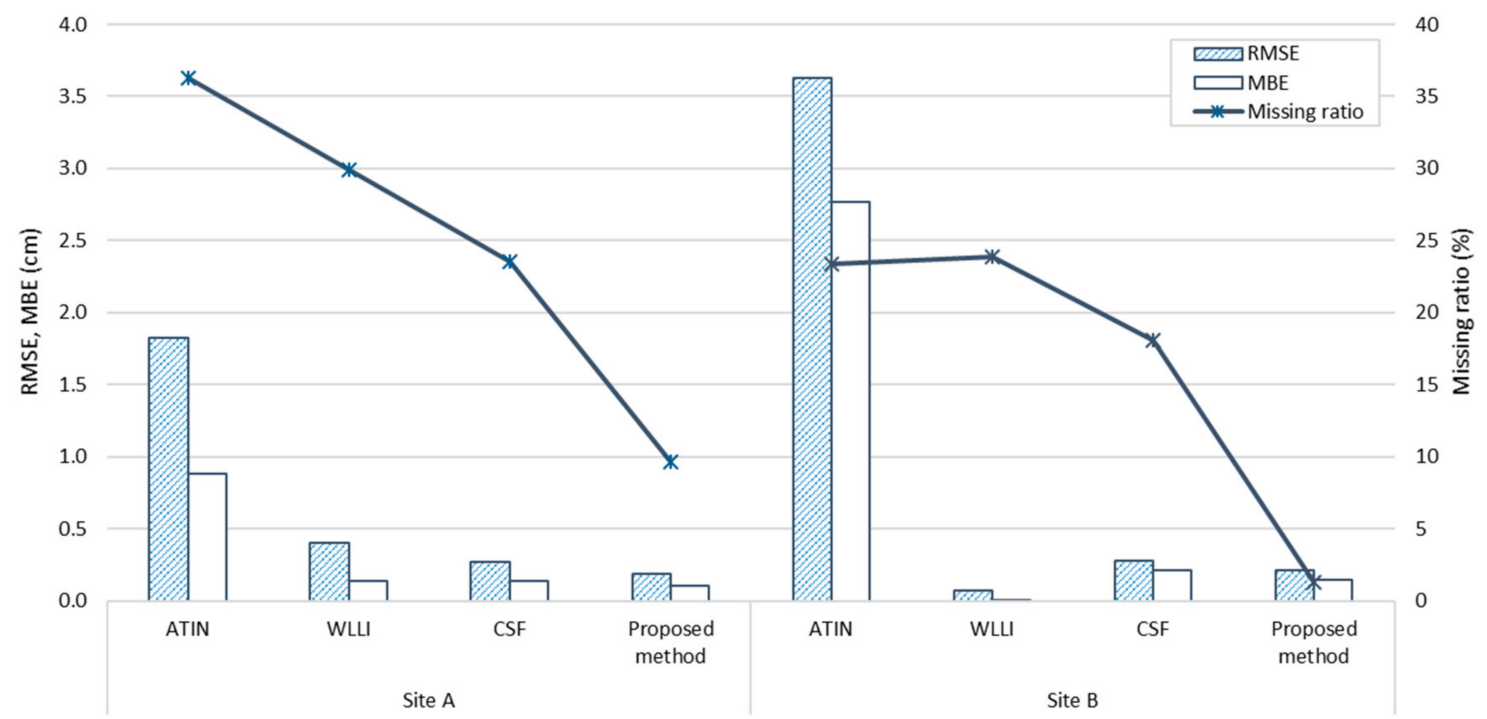

Figure 10. Plot showing filtering results from different methods.

We compared the results of our algorithm with the results obtained using other algorithms to confirm the effectiveness of the adaptive PCA-TIN (Figure 11). Figure 11a-d were produced by other methods and Figure 11g,h were produced by the proposed algorithm. Referencing Figure 11, the empty part in Figure 11a-d should be noted because the ground points actually exist there. On the other hand, our filtering results, depicted in Figure 11g,h, showed better filtering performance in the area with a high slope gradient. 


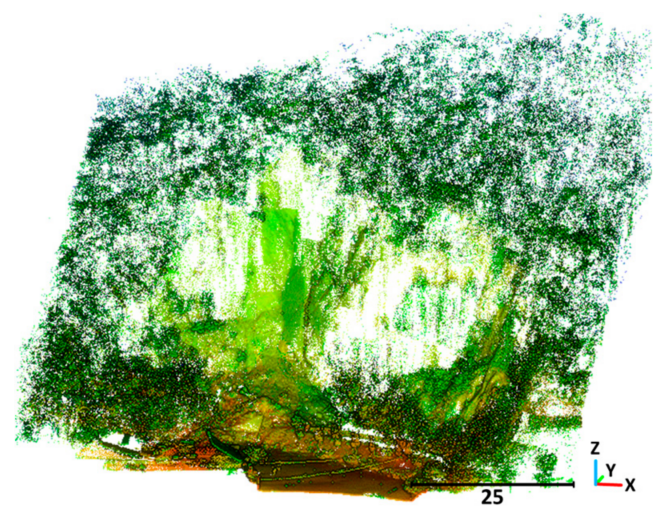

(a)

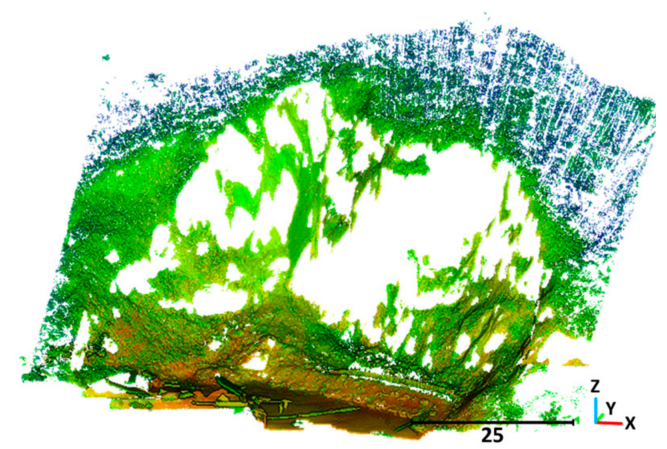

(c)

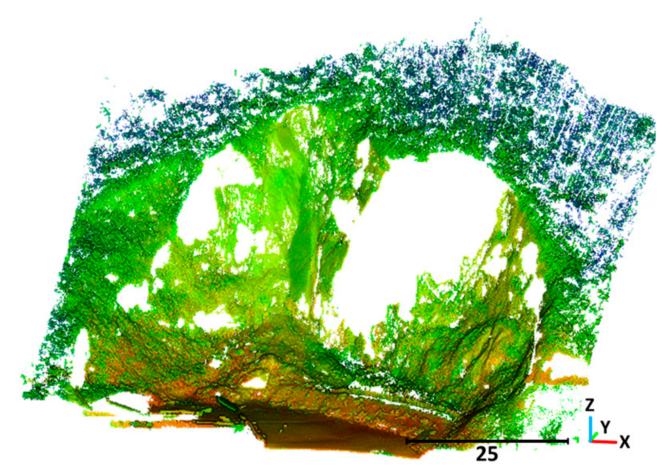

(e)

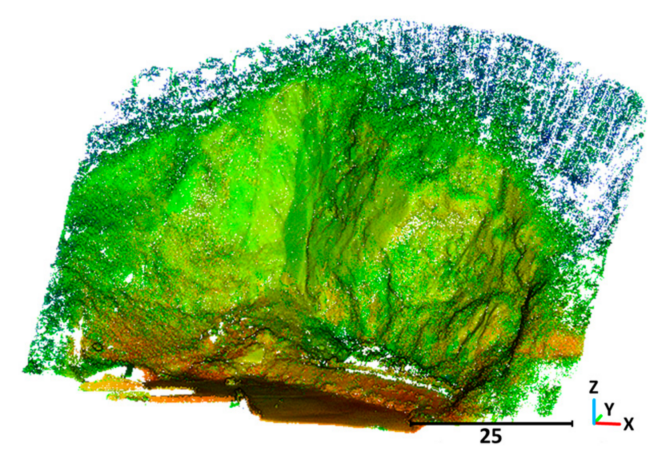

(g)

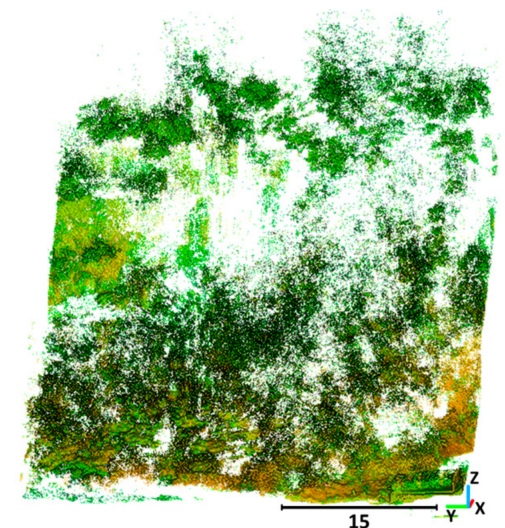

(b)

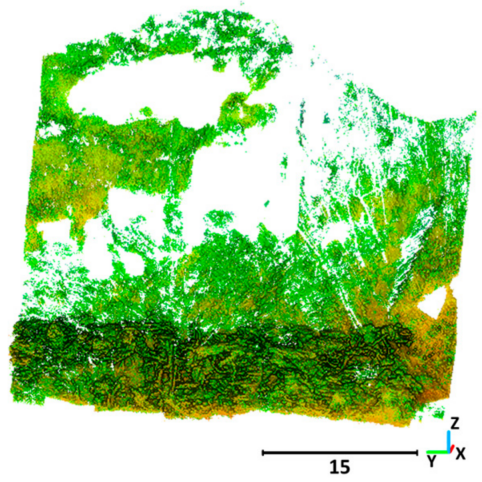

(d)

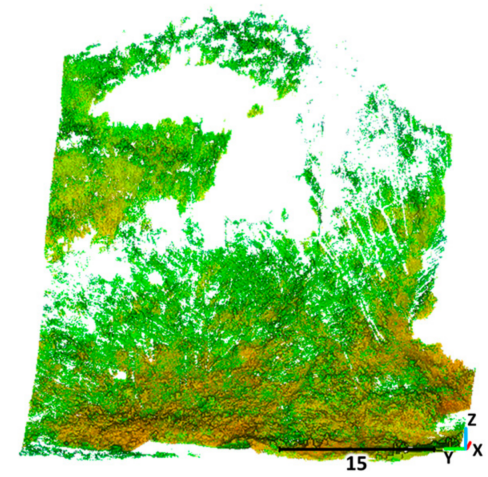

(f)

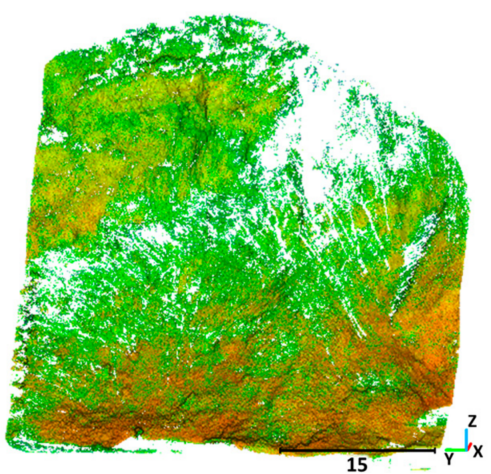

(h)

Figure 11. Comparison of filtering results: (a) site A and (b) site B by ATIN; (c) site A and (d) site B by WLLI; (e) site A and (f) site B by CSF; (g) site A and (h) site B by the proposed method. 


\section{Conclusions}

In this study, an automatic ground filtering algorithm was developed to perform a terrestrial laser scanning data classification in steep-slope areas. Similar algorithms previously developed have limits in classifying ground points in steep slopes using TLS data. Therefore, in this paper, a new process using a slope-based algorithm and adaptive TIN was proposed to efficiently extract only ground points from the TLS point cloud. Considering the fact that steep slopes have a wide range of gradient, the direction of selecting the lowest point was different depending on the slope. After extracting the seed point to the maximum, the performance of the filtering algorithm was improved by applying an adaptive PCA-TIN. Results showed that ground points of hilly areas were effectively extracted. Our algorithm has great potential for TLS-derived DTM construction in vegetated areas with a high slope.

The experiment on two sets of point clouds in steep-slope areas indicated that the proposed method performs well for mountainous areas. The total accuracy values of the generated DTMs in the form of RMSEs were 1.84 and $2.13 \mathrm{~cm}$, respectively, and the proposed method showed better results than other studied methods.

TLS is a very useful ground-based technique that enables the acquisition of geospatial information quickly and accurately. To make ground detection automatically, a ground filtering algorithm needs to be developed. However, there were problems with memory consumption and time efficiency. Future research should aim to improve these problems.

Acknowledgments: The authors are grateful to the Disaster Scientific Investigation (DSI) Division of National Disaster Management Research Institute (NDMI) in Korea for assisting this research and providing the LiDAR data. This research was supported by a grant (17AWMP-B121100-02) from the Water Management Research Program funded by Ministry of Land, Infrastructure, and Transport of Korea government. The authors would also like to thank the anonymous reviewers for their valuable comments and suggestions to improve the quality of the paper.

Author Contributions: Mi-Kyeong Kim, Sangpil Kim, Hong-Gyoo Sohn, Namhoon Kim, and Je-Sung Park were responsible for the research design, data preparation, performing experiments and results analysis; Je-Sung Park provided the data, conducted the field-works; Namhoon Kim contributed to the point cloud data processing; Sangpil Kim conceived the experiments and analyzed the data; Mi-Kyeong Kim designed and implemented the approach; Mi-Kyeong Kim and Hong-Gyoo Sohn wrote the paper; Hong-Gyoo Sohn finally approved the published work.

Conflicts of Interest: The authors declare no conflict of interest.

\section{References}

1. Cruden, D.M. A simple definition of a landslide. Bull. Int. Assoc. Eng. Geol. 1991, 43, 27-29. [CrossRef]

2. Schuster, R.L.; Highland, L.M. Impact of landslides and innovative landslide-mitigation measures on the natural environment. In Proceedings of the International Conference on Slope Engineering, Hong Kong, China, 7-10 December 2003.

3. Kechebour, B.E.L. Relation between Stability of Slope and the Urban Density: Case Study. Procedia Eng. 2015, 114, 824-831. [CrossRef]

4. BBC. China Landslide: 15 Dead, over 100 Missing in Sichuan. BBC News, 24 June 2017. Available online: http:/ / www.bbc.com/news/world-asia-china-40390642 (accessed on 23 August 2017).

5. BBC. Sierra Leone Floods Kill Hundreds as Mudslides Bury Houses. BBC News, 15 August 2017. Available online: http:/ / www.bbc.com/news/world-africa-40926187 (accessed on 23 August 2017).

6. Suk, G.-H. Seoul Faces Increasing Risk of Landslides. The Korea Herald, 18 July 2013. Available online: http:/ / www.koreaherald.com/view.php?ud=20130718000703 (accessed on 23 August 2017).

7. Cho, H.-A. Woomyunsan Landslide, Two Missing Persons Found...18 People Died. NEWSIS, 28 July 2011. Available online: http:/ /www.newsis.com/view/?id=NISX20110728_0008810252 (accessed on 23 August 2017).

8. Aleotti, P.; Chowdhury, R. Landslide hazard assessment: Summary review and new perspectives. Bull. Eng. Geol. Environ. 1999, 58, 21-44. [CrossRef]

9. Baek, M.H.; Kim, T.H. A study on the use of planarity for quick identification of potential landslide hazard. Nat. Hazards Earth Syst. Sci. 2015, 15, 997-1009. [CrossRef] 
10. Hess, D.M.; Leshchinsky, B.A.; Bunn, M.; Benjamin Mason, H.; Olsen, M.J. A simplified three-dimensional shallow landslide susceptibility framework considering topography and seismicity. Landslides 2017, 14, 1677-1697. [CrossRef]

11. Pradhan, B.M.; Mansor, S.; Pirasteh, S.; Buchroithner, M.F. Landslide hazard and risk analyses at a landslide prone catchment area using statistical based geospatial model. Int. J. Remote Sens. 2011, 32, 4075-4087. [CrossRef]

12. Rawat, M.S.; Joshi, V.; Rawat, B.S.; Kumar, K. Landslide movement monitoring using GPS technology: A case study of Bakthang landslide, Gangtok, East Sikkim, India. J. Dev. Agric. Econ. 2011, 3, 194-200.

13. Lee, S.; Chwae, U.; Min, K. Landslide susceptibility mapping by correlation between topography and geological structure: The Janghung area, Korea. Geomorphology 2002, 46, 149-162. [CrossRef]

14. Lee, S.; Lee, M.-J.; Jung, H.-S. Data Mining Approaches for Landslide Susceptibility Mapping in Umyeonsan, Seoul, South Korea. Appl. Sci. 2017, 7, 683. [CrossRef]

15. Glennie, C.L.; Carter, W.E.; Shrestha, R.L.; Dietrich, W.E. Geodetic imaging with airborne LiDAR: The Earth's surface revealed. Rep. Prog. Phys. 2013, 76, 086801. [CrossRef] [PubMed]

16. Telling, J.; Lyda, A.; Hartzell, P.; Glennie, C. Review of Earth science research using terrestrial laser scanning. Earth-Sci. Rev. 2017, 169, 35-68. [CrossRef]

17. Kashani, A.; Olsen, M.; Parrish, C.; Wilson, N. A Review of LIDAR Radiometric Processing: From Ad Hoc Intensity Correction to Rigorous Radiometric Calibration. Sensors 2015, 15, 28099. [CrossRef] [PubMed]

18. Young, A.P.; Olsen, M.J.; Driscoll, N.; Rick, R.E.; Gutierrez, R.; Guza, R.T.; Johnstone, E.; Kuester, F. Comparison of airborne and terrestrial lidar estimates of seacliff erosion in Southern California. ISPRS J. Photogram. Eng. Remote Sens. 2010, 76, 421-427. [CrossRef]

19. Rodríguez-Caballero, E.; Afana, A.; Chamizo, S.; Solé-Benet, A.; Canton, Y. A new adaptive method to filter terrestrial laser scanner point clouds using morphological filters and spectral information to conserve surface micro-topography. ISPRS J. Photogramm. Remote Sens. 2016, 117, 141-148. [CrossRef]

20. Pirasteh, S.; Li, J. Landslides investigations from geoinformatics perspective: Quality, challenges, and recommendations. Geomat. Nat. Hazards Risk 2016, 1-18. [CrossRef]

21. Guan, H.; Li, J.; Yu, Y.; Zhong, L.; Ji, Z. DEM generation from lidar data in wooded mountain areas by cross-section-plane analysis. Int. J. Remote Sens. 2014, 35, 927-948. [CrossRef]

22. Liu, X. Airborne LiDAR for DEM generation: Some critical issues. Prog. Phys. Geogr. 2008, 32, 31-49.

23. Mongus, D.; Žalik, B. Parameter-free ground filtering of LiDAR data for automatic DTM generation. ISPRS J. Photogramm. Remote Sens. 2012, 67, 1-12. [CrossRef]

24. Kobler, A.; Pfeifer, N.; Ogrinc, P.; Todorovski, L.; Oštir, K.; Džeroski, S. Repetitive interpolation: A robust algorithm for DTM generation from Aerial Laser Scanner Data in forested Terrain. Remote Sens. Environ. 2007, 108, 9-23. [CrossRef]

25. Axelsson, P. DEM generation from laser scanner data using adaptive TIN models. Int. Arch. Photogramm. Remote Sens. 2000, XXXIII, 340-346.

26. Evans, J.S.; Hudak, A.T. A multiscale curvature algorithm for classifying discrete return LiDAR in forested environments. IEEE Trans. Geosci. Remote Sens. 2007, 45, 1029-1038. [CrossRef]

27. Gallay, M. Direct acquisition of data: Airborne laser scanning. In Geomorphological Techniques; British Society for Geomorphology: London, UK, 2013; pp. 1-17.

28. Vosselman, G. Slope based filtering of laser altimetry data. Int. Arch. Photogramm. Remote Sens. 2000, XXXIII, 935-942.

29. Yunfei, B.; Guoping, L.; Chunxiang, C.; Xiaowen, L.; Hao, Z.; Qisheng, H.; Linyan, B.; Chaoyi, C. Classification of LIDAR point cloud and generation of DTM from LIDAR height and intensity data in forested area. Int. Arch. Photogram. Remote Sens. Spat. Inf. Sci. 2008, XXXVII, 313-318.

30. Meng, X.; Currit, N.; Zhao, K. Ground Filtering Algorithms for Airborne LiDAR Data: A Review of Critical Issues. Remote Sens. 2010, 2, 833. [CrossRef]

31. Chen, Z.; Gao, B.; Devereux, B. State-of-the-art: DTM generation using airborne LIDAR data. Sensors 2017, 17, 150. [CrossRef] [PubMed]

32. Li, Y.; Yong, B.; Wu, H.; An, R.; Xu, H.; Xu, J.; He, Q. Filtering Airborne Lidar Data by Modified White Top-Hat Transform with Directional Edge Constraints. Photogramm. Eng. Remote Sens. 2014, 80, $133-141$. [CrossRef] 
33. Mongus, D.; Lukač, N.; Žalik, B. Ground and building extraction from LiDAR data based on differential morphological profiles and locally fitted surfaces. ISPRS J. Photogramm. Remote Sens. 2014, 93, 145-156. [CrossRef]

34. Sithole, G.; Vosselman, G. Experimental comparison of filter algorithms for bare-Earth extraction from airborne laser scanning point clouds. ISPRS J. Photogramm. Remote Sens. 2004, 59, 85-101. [CrossRef]

35. Chen, C.; Li, Y.; Yan, C.; Dai, H.; Liu, G.; Guo, J. An improved multi-resolution hierarchical classification method based on robust segmentation for filtering ALS point clouds. Int. J. Remote Sens. 2016, 37, 950-968. [CrossRef]

36. Sithole, G. Filtering of laser altimetry data using a slope adaptive filter. Int. Arch. Photogramm. Remote Sens. 2001, 34, 203-210.

37. Chen, Q.; Gong, P.; Baldocchi, D.; Xie, G. Filtering airborne laser scanning data with morphological methods. Photogramm. Eng. Remote Sens. 2007, 73, 175-185. [CrossRef]

38. Zhang, K.; Chen, S.C.; Whitman, D.; Shyu, M.L.; Yan, J.; Zhang, C. A progressive morphological filter for removing nonground measurements from airborne LIDAR data. IEEE Trans. Geosci. Remote Sens. 2003, 41, 872-882. [CrossRef]

39. Błaszczak-Bąk, W.; Janowski, A.; Kamiński, W.; Rapiński, J. Application of the Msplit method for filtering airborne laser scanning data-sets to estimate digital terrain models. Int. J. Remote Sens. 2015, 36, 2421-2437. [CrossRef]

40. Kraus, K.; Pfeifer, N. Determination of terrain models in wooded areas with airborne laser scanner data. ISPRS J. Photogramm. Remote Sens. 1998, 53, 193-203. [CrossRef]

41. Rapinski, J.; Kaminski, W.; Janowski, A.; Blaszczak-Bak, W. ALS Data Filtration with Fuzzy Logic. J. Indian Soc. Remote Sens. 2011, 39, 591-597. [CrossRef]

42. Wasowski, J.; Bovenga, F. Remote sensing of landslide motion with emphasis on satellite multitemporal interferometry applications: An overview. In Landslide Hazards, Risks and Disasters; Academic Press: Boston, MA, USA, 2015; pp. 345-403.

43. Pirotti, F.; Guarnieri, A.; Vettore, A. Ground filtering and vegetation mapping using multi-return terrestrial laser scanning. ISPRS J. Photogramm. Remote Sens. 2013, 76, 56-63. [CrossRef]

44. Meng, X.; Wang, L.; Silván-Cárdenas, J.L.; Currit, N. A multi-directional ground filtering algorithm for airborne LIDAR. ISPRS J. Photogramm. Remote Sens. 2009, 64, 117-124. [CrossRef]

45. Wang, C.; Menenti, M.; Stoll, M.P.; Feola, A.; Belluco, E.; Marani, M. Separation of ground and low vegetation signatures in LiDAR measurements of salt-marsh environments. IEEE Trans. Geosci. Remote Sens. 2009, 47, 2014-2023. [CrossRef]

46. National Assembly. Prevention of Steep Slope Disasters Act; South Koreas National Assembly: Seoul, Korea, 2016.

47. MPSS. 2016 National Security White Paper-700-Day Footprint for the Safety of the People; MPSS: Sejong, Korea, 2016.

48. Pyun, H. 'Crumbling' Five-Day Specimen Inspection of Twenty-Eight Steep Slopes just before the Collapse. NEWSIS, 28 December 2016. Available online: http://www.newsis.com/ar_detail/view.html/?ar_id= NISX20160319_0013968462\&cID=10201\&pID=10200 (accessed on 24 September 2017).

49. RIEGL. Product Detail: RIEGL VZ-2000. 2017. Available online: http://www.riegl.com/nc/products/ terrestrial-scanning/produktdetail/product/scanner/45/ (accessed on 16 July 2017).

50. RIEGL. Datasheet of RiSCAN PRO. 2016. Available online: http://www.riegl.com/uploads/tx_ pxpriegldownloads/11_DataSheet_RiSCAN-PRO_2016-09-19.pdf (accessed on 16 July 2017).

51. Kolecka, N. Vector algebra for Steep Slope Model analysis. Landf. Anal. 2012, 21, 17-25.

52. Zhang, W.; Qi, J.; Wan, P.; Wang, H.; Xie, D.; Wang, X.; Yan, G. An easy-to-use airborne LiDAR data filtering method based on cloth simulation. Remote Sens. 2016, 8, 501. [CrossRef]

(C) 2017 by the authors. Licensee MDPI, Basel, Switzerland. This article is an open access article distributed under the terms and conditions of the Creative Commons Attribution (CC BY) license (http:/ / creativecommons.org/licenses/by/4.0/). 